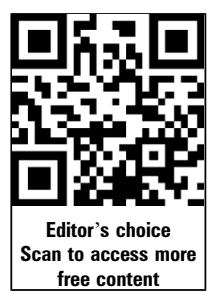

- Additional material is published online only. To view please visit the journal online (http://dx.doi.org/10.1136/jech2015-205673)

${ }^{1}$ Institute of Social and Preventive Medicine, Lausanne University Hospital, Lausanne, Switzerland

${ }^{2}$ Epidemiology Unit, ASL TO3 Piedmont Region, Grugliasco (TO), Italy

${ }^{3}$ Public Health and Paediatric Sciences Department,

University of Turin, Turin, Italy ${ }^{4}$ Department of Epidemiology and Environmental Health, Regional Environment Protection Agency, Grugliasco (TO), Italy

${ }^{5}$ Department of Clinical and Biological Sciences, University of Turin, Turin, Italy

\section{Correspondence to}

Dr Silvia Stringhini, University Institute of Social and Preventive Medicine (IUMSP) Lausanne University Hospital, Biopôle 2-Route de la Corniche 10, Lausanne 1010

Switzerland;

silvia.stringhini@chuv.ch

Received 24 February 2015 Revised 8 June 2015

Accepted 24 June 2015

Published Online First

16 July 2015

\title{
Decreasing educational differences in mortality over 40 years: evidence from the Turin Longitudinal Study (Italy)
}

Silvia Stringhini, ${ }^{1}$ Teresa Spadea, ${ }^{2}$ Morena Stroscia, ${ }^{3}$ Roberta Onorati, ${ }_{1}{ }^{2}$ Moreno Demaria, ${ }^{4}$ Nicolás Zengarini, ${ }^{5}$ Giuseppe Costa ${ }^{2,5}$

\section{ABSTRACT}

Background Recent studies suggest that inequalities in premature mortality have continued to rise over the last decade in most European countries, but not in southern European countries.

Methods In this study, we assess long-term trends (1971-2011) in absolute and relative educational inequalities in all-cause and cause-specific mortality in the Turin Longitudinal Study (Turin, Italy), a recordlinkage study including all individuals resident in Turin in the 1971, 1981, 1991 and 2001 censuses, and aged 30-99 years (more than 2 million people). We examined mortality for all causes, cardiovascular disease (CVD), all cancers and specific cancers (lung, breast), as well as smoking and alcohol-related mortality.

Results Overall mortality substantially decreased in all educational groups over the study period, although cancer rates only slightly declined. Absolute inequalities decreased for both genders (SII=962/694 in men/women in 1972-1976 and SII=531/259 in 2007-2011, $p<0.01)$. Among men, absolute inequalities for CVD and alcohol-related causes declined $(p<0.05)$, while remaining stable for other causes of death. Among women, declines in absolute inequalities were observed for CVD, smoking and alcohol-related causes and lung cancer $(p<0.05)$. Relative inequalities in all-cause mortality remained stable for men and decreased for women (RIl=1.92/2.03 in men/women in 1972-1976 and $R \|=2.15 / 1.32$ in 2007-2011). Among men, relative inequalities increased for smoking-related causes, while among women they decreased for all cancers, $C V D$, smoking-related causes and lung cancer $(p<0.05)$.

Conclusions Absolute inequalities in mortality strongly declined over the study period in both genders. Relative educational inequalities in mortality were generally stable among men; while they tended to narrow among women. In general, this study supports the hypothesis that educational inequalities in mortality have decreased in southern European countries.

\section{INTRODUCTION}

Age-standardised mortality rates (ASMR) have consistently decreased over the past 50 years in most high-income countries ${ }^{1-3}$ due to major changes in socioeconomic conditions, lifestyle behaviours, and improvements in disease prevention and treatment. ${ }^{45}$ Yet, these favourable trends have not benefited all population groups equally, and widening inequalities in mortality by socioeconomic status have been described in Europe and North America up to the end of the 20th century. ${ }^{3}{ }^{6-9}$ Recent studies using data for the first decade of the 21st century suggest that relative inequalities in mortality have continued to rise in most European countries but not in southern European countries such as Italy or Spain. ${ }^{10-14}$ Absolute inequalities among men, on the contrary, have narrowed for most European countries, ${ }^{10}$ but in some countries such as Norway, they increased among women. ${ }^{13}$

In Europe, the existence of a north-south divide (and recently of an east-south divide) relatively to the magnitude of social differences in mortality has been widely described, with social inequalities in mortality being smaller in southern than in northern and eastern European countries. ${ }^{10} 1516$ In Italy, social inequalities in mortality are widely reported but, as expected, they are generally smaller than in northern European countries, ${ }^{15}{ }^{17}$ also as a consequence of small or inexistent social gradients in major lifestyle-related risk factors. ${ }^{18} 19$ Patterns of unhealthy behaviours, ${ }^{20} 21$ exposure to environmental hazards ${ }^{22-25}$ or stressful situations, ${ }^{24} 26$ early life experiences, ${ }^{27}$ access to/use of medical care, ${ }^{28} 29$ access to health information ${ }^{30} 31$ and to resources mediating the physiological consequences of stress (ie, social relationships and support, cultural capital) $)^{3032}$ are among the factors potentially explaining social inequalities in mortality. On the one hand, between-country variations in the social patterning of these factors may account for the observed geographical differences in social inequalities in mortality. On the other hand, within countries, the social distribution of these factors may change over time, impacting social inequalities in mortality and their trends up to decades later.

Over the past four decades, Italy has experienced great economic, social and cultural transformations that have potentially impacted social inequalities in morbidity and mortality. In this study, we aim to examine long-term trends in absolute and relative educational inequalities in overall and cause-specific mortality in Italy. To do this, we use data from the Turin Longitudinal Study (TLS) (Italy) that has social and mortality records since 1971 . We particularly focus on specific causes of mortality that are more linked to the socioeconomic and cultural transformation that occurred in Italy over the past 50 years: cancer and cardiovascular mortality, smoking-related and alcohol-related mortality, lung cancer and breast cancer mortality.

\section{DATA AND METHODS}

\section{Study population}

Data were drawn from the TLS, a health monitoring system containing information from censuses 
and routinely registered events in Turin, a city of about one million inhabitants located in northwest Italy. TLS is based on the historical population register that includes records for all individuals who were resident in Turin at least once since 1971. Through individual record linkage procedures, the TLS also includes all socioeconomic information collected through the censuses of 1971, 1981, 1991 and 2001 (2011 still not available) and information about health outcomes derived from the archives of causes of death (since 1971), hospital admissions (since 1995), cancer registries (since 1986), diabetes register (since 2002), outpatient visits (since 2000) and drug prescriptions (since 1997).

This specific investigation was designed as a follow-up study for mortality extending from the 1971 census to 31 December 2011. The cohort has been built with the dynamic approach of an open cohort; the entry point is, therefore, either the 1971 census for people 30 years or older and resident in the city at that time, the date of immigration for new residents $\geq 30$ years old, or the date of the 30th birthday. Dropouts were censored at the date of emigration or, if unknown, at the following census. The age limit 30-99 was chosen for main analysis, as educational level is relatively stable after this age. Analyses were then repeated and restricted to the age range 30-64.

\section{Measures \\ Mortality}

All-cause and cause-specific mortality were examined. The International Classification of Diseases, 9th Revision (ICD-9), codes were used to define the following causes of death: cancer (ICD-9 140-208), cardiovascular disease (CVD) (ICD-9 390459), lung cancer (ICD-9 162) and breast cancer (ICD-9 174). Smoking and alcohol-related mortality were defined according to the conditions and corresponding etiologic fractions defined by Single et al and by the Centers for Disease Control and Prevention, for tobacco and alcohol-related causes, respectively. ${ }^{33-35}$

\section{Education}

Education was the highest attained level of education across the entire follow-up period of each individual, and was classified into four levels: primary (including preprimary education and corresponding to International Standard Classification of Education (ISCED) levels 0-1), lower secondary and vocational (ISCED 2 and $3 \mathrm{C}$ ), upper secondary (ISCED $3 \mathrm{~A}$ and $3 \mathrm{~B}$ ) and college (including all stages of post-secondary education, ISCED 4-6).

\section{Statistical analysis}

ASMRs, directly standardised to the European standard population $^{36}$ were calculated using Poisson regression models separately by educational group, gender and period (stratified in eight 5 -year intervals from 1972 to 2011).

Relative inequalities were examined through the Relative Index of Inequality (RII) and absolute inequalities with the Slope Index of Inequality (SII). ${ }^{37}$ These are regression-based indexes, summarising into a single value the whole gradient of the association between a health problem (in our case mortality) and a hierarchical socioeconomic indicator (education). Since they take into account both the size of each socioeconomic category and its relative position in the educational hierarchy, their main advantage is that they allow comparisons of inequalities over time, even when the social distribution of the population has changed. Specifically, the RII corresponds to the ratio, and the SII to the difference of the rates estimated at the two extreme points of the social hierarchy on a theoretical continuous scale, ranging from zero (highest level of education) to 1 (lowest level of education).

Joinpoint regression analysis was used to examine time trends in RII and SII. This allows identifying the best-fitting points where a statistically significant change in the trends occurred over the eight 5 -year intervals, ${ }^{38}$ The resulting segments between joinpoints can be described by an annual per cent change (APC), which in our case represents the mean 5-year change. Joinpoint analyses were performed using the 'Joinpoint' software from the Surveillance Research Program of the US National Cancer Institute (Joinpoint Regression Program, V.4.2.0.1. May 2015; Statistical Research and Applications Branch, National Cancer Institute).

\section{RESULTS}

A total of 395276 deaths (194 443 among men and 200833 among women) occurred between 1972 and 2011, over a total of 26804942 person-years at risk. The absolute number of deaths per decade decreased slightly between 1972-1981 and 2002-2011, and ASMR consistently declined for both men and women and for all educational groups (table 1). The proportion of the population with college education increased (from $8 \%$ and 4\% in 1972-1981 in men and women, respectively, to $16 \%$ and $14 \%$ in 2002-2011) and that of the population with less than primary school education largely decreased (from $48 \%$ and $59 \%$ to $16 \%$ and $26 \%$ ). Figure $1 \mathrm{~A}$ shows 40 -year trends in ASMR by gender and educational level for all-cause mortality. Over the study period, mortality rates were consistently higher in men than in women, and strong educational differences were observed, with rates being higher in low versus high educational groups across the study period. Mortality rates of women with university education tended to increase over the last decade. Results for relative and absolute inequalities are shown in figure 1B. Absolute inequalities in mortality almost halved over the study period for both men and women (SII $=962 / 694,95 \%$ CI 885 to $1039 / 566$ to 821 in men/women in 1972-1976 and $\mathrm{SII}=531 / 259,95 \%$ CI 369 to $693 / 159$ to 359 in men/women in 2007-2011, $\mathrm{APC}=-5.9 /-15.7, \mathrm{p}=0.003)$. Relative inequalities increased in men until 2001 and then started to decline in the last decade, although the change in the trend was not statistically significant. Among women, relative inequalities showed a decreasing pattern across the study period $(\mathrm{RII}=2.03,95 \% \mathrm{CI}$ 1.70 to 2.17 in $1972-1976$ and $\mathrm{RII}=1.32,95 \%$ CI 1.22 to 1.43 in 2007-2011, APC $=-6.6, \mathrm{p}=0.002$ ).

Trends in absolute and relative inequalities for cause-specific mortality in men are shown in figure 2. Absolute inequalities remained large and stable across the study period for all cancers, smoking-related and lung cancer mortality. A decrease in absolute inequalities was observed for CVD mortality $(\mathrm{APC}=-15.5$, $\mathrm{p}=0.006$ ), but inequalities were still large at the end of the study period ( $\mathrm{SII}=123.7$, 95\% CI 43.7 to 203.7). Absolute inequalities in alcohol-related mortality also declined (APC= $-8.7, p=0.005)$ and were small at the end of the study period. Concerning relative inequalities, they were large and stable across the study period for all cancers and CVD mortality. A non-significant decrease was observed for alcohol-related mortality, and a borderline significant increase was noted for smoking-related mortality $(\mathrm{APC}=3.5, \mathrm{p}=0.05)$. Figure 3 presents trends in absolute and relative inequalities for causespecific mortality among women. Absolute inequalities in mortality were generally very small among women with the exception of CVD mortality, for which they remained large up to the end of the study period (SII=90.9, 95\% CI 48.3 to 133.7) despite a sharp decline ( $\mathrm{APC}=-16.1, \mathrm{p}=0.003$ ). Relative 
Table 1 Mortality by gender, educational level and period (1972-2011), Turin Longitudinal Study, age 30-99 years

\begin{tabular}{|c|c|c|c|c|c|c|c|c|c|c|}
\hline \multirow[b]{2}{*}{ Decade } & \multicolumn{5}{|l|}{$\begin{array}{l}\text { Men } \\
\text { Educational level }\end{array}$} & \multicolumn{5}{|l|}{$\begin{array}{l}\text { Women } \\
\text { Educational level }\end{array}$} \\
\hline & College & Upper-secondary & $\begin{array}{l}\text { Lower secondary/ } \\
\text { vocational }\end{array}$ & Primary & Total & College & Upper-secondary & $\begin{array}{l}\text { Lower secondary/ } \\
\text { vocational }\end{array}$ & Primary & Total \\
\hline \multicolumn{11}{|l|}{ 1972-1981 } \\
\hline Deaths & 2743 & 4626 & 9875 & 36597 & 53841 & 496 & 2931 & 7602 & 41812 & 52841 \\
\hline Person-years, N (\%) & 247927 (8) & $493573(16)$ & 898468 (29) & 1510701 (48) & 3150669 & 138388 (4) & 396461 (11) & 952252 (26) & $2181033(59)$ & 3668134 \\
\hline $\operatorname{ASMR}^{*}(95 \% \mathrm{Cl})$ & 1588 (1527 to 1651$)$ & 1693 (1640 to 1746$)$ & 1905 (1862 to 1948$)$ & 2311 (2287 to 2336 ) & 2186 (2166 to 2205$)$ & 776 (703 to 857 ) & 894 (861 to 928 ) & 1048 (1024 to 1073$)$ & 1340 (1326 to 1353$)$ & 1288 (1277 to 1299$)$ \\
\hline RR $(95 \% \mathrm{Cl})$ & 1.00 & 1.11 (1.00 to 1.24$)$ & 1.27 (1.15 to 1.41$)$ & 1.76 (1.58 to 1.96$)$ & & 1.00 & 1.19 (1.07 to 1.32$)$ & 1.43 (1.30 to 1.58$)$ & 1.89 (1.72 to 2.09 ) & \\
\hline \multicolumn{11}{|l|}{ 1982-1991 } \\
\hline Deaths & 2891 & 5538 & 11284 & 29176 & 48889 & 812 & 3975 & 9661 & 36280 & 50728 \\
\hline Person-years & 327801 (11) & 633349 (21) & $1000499(33)$ & $1109118(36)$ & 3070767 & $229858(6)$ & 543052 (15) & $1096091(30)$ & $1731657(48)$ & 3600658 \\
\hline $\operatorname{ASMR}^{*}(95 \% \mathrm{Cl})$ & 1217 (1171 to 1265$)$ & 1441 (1400 to 1482 ) & 1570 (1539 to 1602 ) & 1928 (1905 to 1952$)$ & 1756 (1740 to 1772 ) & 624 (580 to 672 ) & 788 (763 to 814$)$ & 883 (865 to 901$)$ & 1077 (1065 to 1090$)$ & 1019 (1010 to 1029$)$ \\
\hline RR $(95 \% \mathrm{Cl})$ & 1.00 & 1.29 (1.07 to 1.55$)$ & 1.69 (1.41 to 2.03$)$ & 2.43 (2.01 to 2.94$)$ & & 1.00 & $1.42(1.28$ to 1.57$)$ & 1.53 (1.39 to 1.68$)$ & 1.78 (1.61 to 1.95$)$ & \\
\hline \multicolumn{11}{|l|}{ 1992-2001 } \\
\hline Deaths & 3421 & 6461 & 13243 & 23400 & 46525 & 1220 & 4762 & 11546 & 30940 & 48468 \\
\hline Person-years & 405848 (13) & 771223 (25) & $1088682(36)$ & 763732 (25) & 3029485 & $339838(10)$ & $719163(21)$ & $1173580(33)$ & 1273531 (36) & 3506112 \\
\hline $\operatorname{ASMR}^{*}(95 \% \mathrm{Cl})$ & 966 (933 to 1000$)$ & 1147 (1118 to 1176$)$ & 1352 (1329 to 1376$)$ & 1664 (1636 to 1693$)$ & 1414 (1401 to 1428$)$ & 489 (462 to 518 ) & 689 (669 to 710$)$ & 737 (724 to 751$)$ & 876 (860 to 893 ) & 807 (800 to 815$)$ \\
\hline RR $(95 \% \mathrm{Cl})$ & 1.00 & 1.21 (1.06 to 1.39 ) & 1.61 (1.39 to 1.85$)$ & 1.89 (1.62 to 2.21$)$ & & 1.00 & 1.42 (1.28 to 1.57$)$ & 1.53 (1.39 to 1.68$)$ & 1.78 (1.61 to 1.95$)$ & \\
\hline \multicolumn{11}{|l|}{$2002-2011$} \\
\hline Deaths & 4331 & 7910 & 14527 & 18420 & 45188 & 2393 & 5828 & 13431 & 27144 & 48796 \\
\hline Person-years & 499990 (16) & $955192(30)$ & $1190392(38)$ & $521261(16)$ & 3166835 & $490583(14)$ & 958097 (27) & $1237439(34)$ & $926163(26)$ & 3612282 \\
\hline $\operatorname{ASMR}^{*}(95 \% \mathrm{Cl})$ & 837 (812.5 to 863.4$)$ & 945 (924 to 966$)$ & 1127 (1108 to 1146$)$ & 1320 (1290 to 1353$)$ & 1123 (1112 to 1134$)$ & 545 (523 to 568 ) & 594 (579 to 610$)$ & 643 (631 to 654$)$ & 742 (719 to 767$)$ & 672 (665 to 678$)$ \\
\hline RR $(95 \% \mathrm{Cl})$ & 1.00 & 1.20 (1.05 to 1.38$)$ & 1.66 (1.45 to 1.91$)$ & 1.99 (1.72 to 2.31$)$ & & 1.00 & 1.10 (1.01 to 1.20$)$ & 1.18 (1.09 to 1.28$)$ & 1.28 (1.18 to 1.38$)$ & \\
\hline
\end{tabular}

ASMR, age-standardised mortality rates; $R R$, relative risk. 


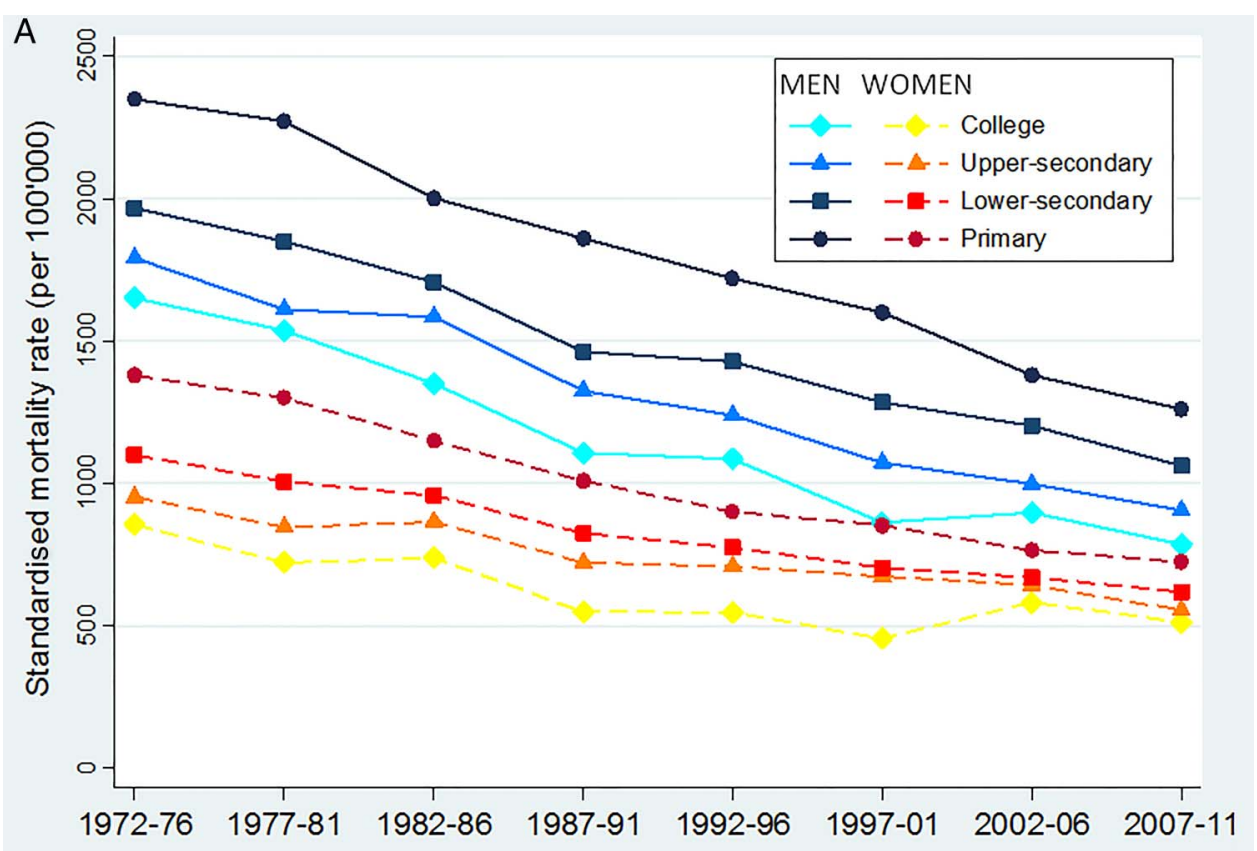

B

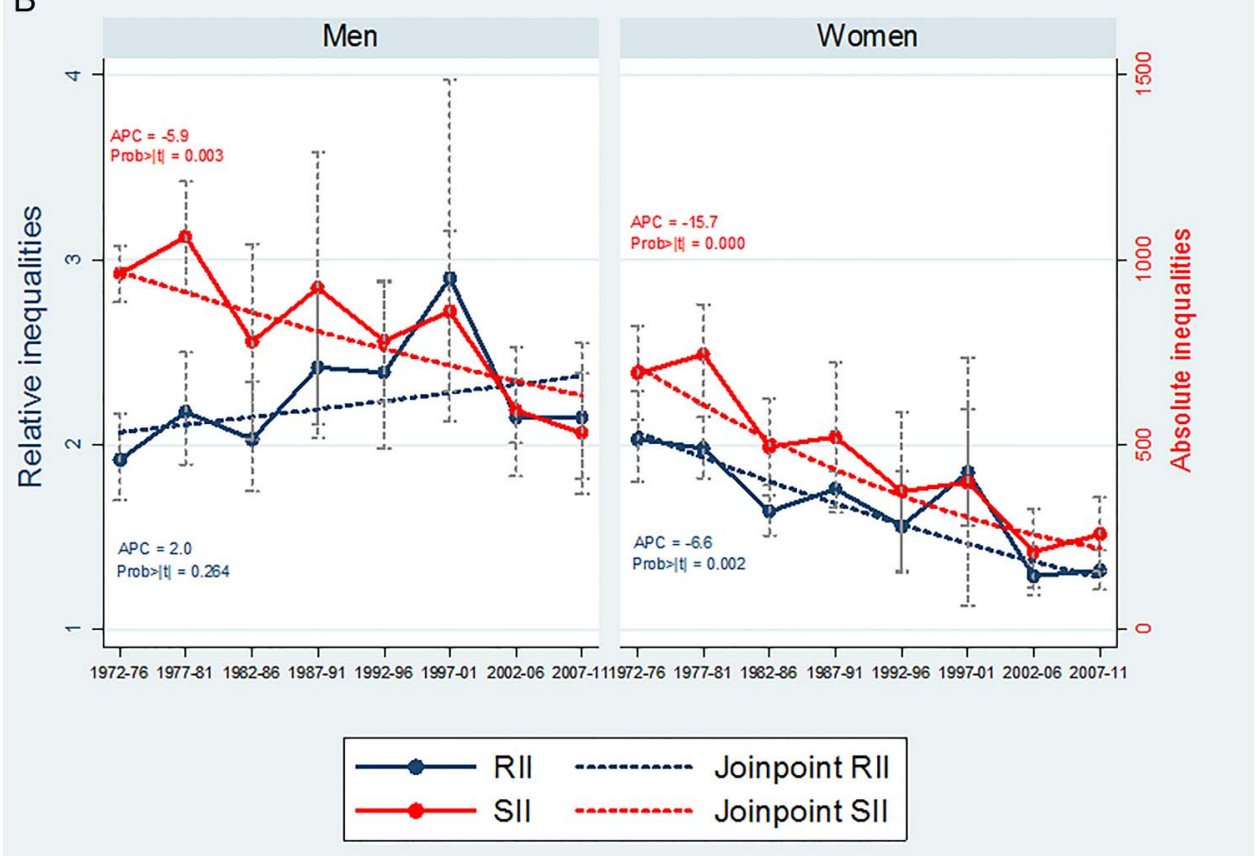

Figure 1 The 40-year trends in (A) standardised mortality rates by educational level and (B) relative and absolute inequalities in all-cause mortality among men and women aged 30-99 years of the Turin Longitudinal Study (1972-2011). (B) The figure showing SII, RII (and their 95\% CI) and the linear prediction for trend across the four decades. The lower secondary education category includes vocational education (ISCED level 3C) (RII, Relative Index of Inequality; SII, Slope Index of Inequality; $p$ trend, p for test for linear trend.).

inequalities declined for all causes of death examined apart from breast cancer and alcohol-related mortality (stable), and they were modest or inexistent at the end of the study period. Of note, SII and RII analyses suggest that absolute inequalities in breast cancer mortality were consistently very low over the study period, and relative inequalities showed a non-significant inversed pattern favouring women with low education. However, a closer look at ASMR (see online supplementary figure S6) indicates that women with secondary education experienced the highest breast cancer mortality rates across the study period, while women with primary and university education had generally lower ASMR. Online supplementary table S1 summarises trends in absolute and relative inequalities in mortality in men and women.

Online supplementary figures S1-S6 show 40-year trends in ASMR by gender and educational group for the specific causes of death examined. An increase in ASMR was observed in the last 10 years for women with a high educational level, for most causes of death. Analysis restricted to the age group 30-64 years yielded similar results to those reported in main analysis in men. In women, results were similar apart from a weaker reduction in inequalities in all-cause and cancer mortality, and from relative inequalities in cardiovascular mortality that remained stable for the age group 30-64, but decreased for the age group 30-99. 

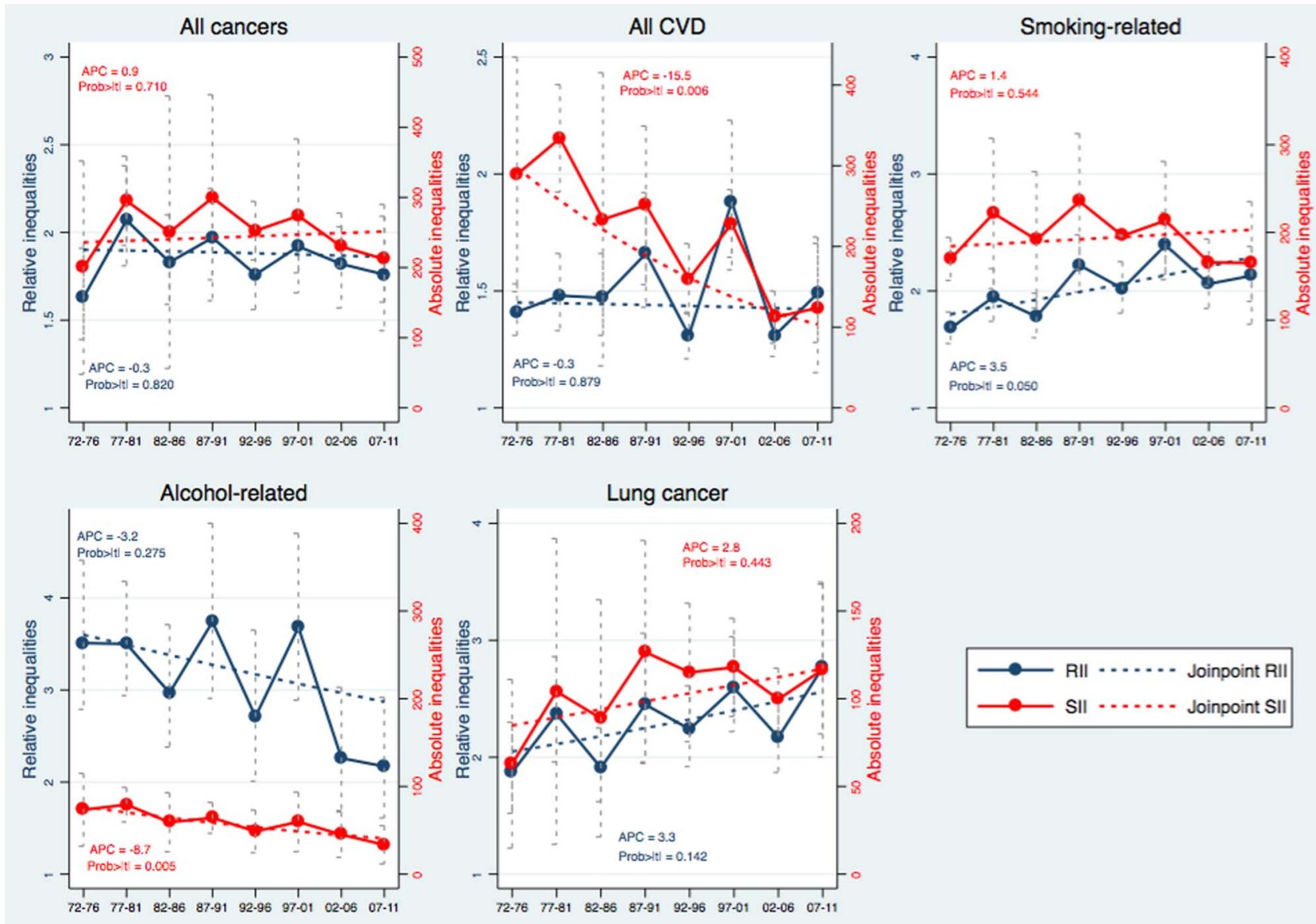

Figure 2 Trends in relative and absolute inequalities for cause-specific mortality among men of the Turin Longitudinal Study (1972-2011), age 30-99 years. The figure showing SII, RII (and their 95\% Cl) and the linear prediction for trend across the four decades (CVD, Cardiovascular disease; SII, Slope Index of Inequality; RII, Relative Index of Inequality; $p$ trend, $p$ for test for linear trend).

Different results in women were also observed for lung cancer mortality as inequalities remained stable in the age group 30-64 but declined in the age group 30-99 (see online supplementary figures S7-S9).

\section{DISCUSSION}

In this study, we examined long-term trends in educational inequalities in all-cause and cause-specific mortality in the Italian city of Turin. We observed a sharp decline in overall and cause-specific mortality over the 40 -year study period for both men and women and in all educational groups. Among men, absolute inequalities in mortality declined for all causes, CVD and alcohol-related mortality, and remained stable for cancer (all cancers, lung cancer); relative inequalities in mortality remained stable for all causes examined apart from smoking-related causes (increase). Among women, absolute inequalities declined for all causes, CVD, alcohol-related and smoking-related mortality, while remaining stable for the other causes examined; relative inequalities declined for all causes examined apart from alcohol-related and breast cancer mortality (stable). Despite the observed positive trends, large inequalities in mortality were still observed at the end of the study period, especially among men.

As discussed earlier, few studies have examined recent trends in educational inequalities in mortality, but those that have done so have observed similar trends than those reported here for southern European countries. For example, Mackenbach et al ${ }^{10}$ recently reported that relative inequalities in premature mortality increased in most populations in the north, west and east of Europe, but not in the south. Italy has experienced dramatic transformations during the period covered by our study. Since the 1970s, after the previous postwar demographic and industrial boom, economic downturns have alternated with short periods of recovery; the female employment rate has steadily increased (but that of males has declined) ${ }^{39}$; a universal national healthcare system (NHS) on the model of the British National Health Service was established in 1978; years of compulsory education have substantially increased, and a rapid urbanisation and a positive migration balance started being observed since the 1970s. ${ }^{40}{ }^{41}$ Reproductive behaviours also radically changed in Italy over the years, with declines in fertility rates and increased age at childbearing, especially among highly educated women. ${ }^{42}$ Moreover, the social transition of risk factors for chronic diseases from the higher to the lower socioeconomic groups seems to have occurred in Italy over the past 50 years ${ }^{43}$ at a slower pace that in the rest of continental and northern Europe.

A first consideration is related to the healthcare system. Before the establishment of NHS, employment-based sickness funds ensured different levels of healthcare to the working population and their families, but a considerable proportion of people was not covered. Since the early 1980s, the NHS, which is built on the principle of equal access to services, has ensured universal coverage to all inhabitants almost free of charge. In this respect, it is likely that medical advances over the past 40 years have benefited all population groups equally in Italy, at 

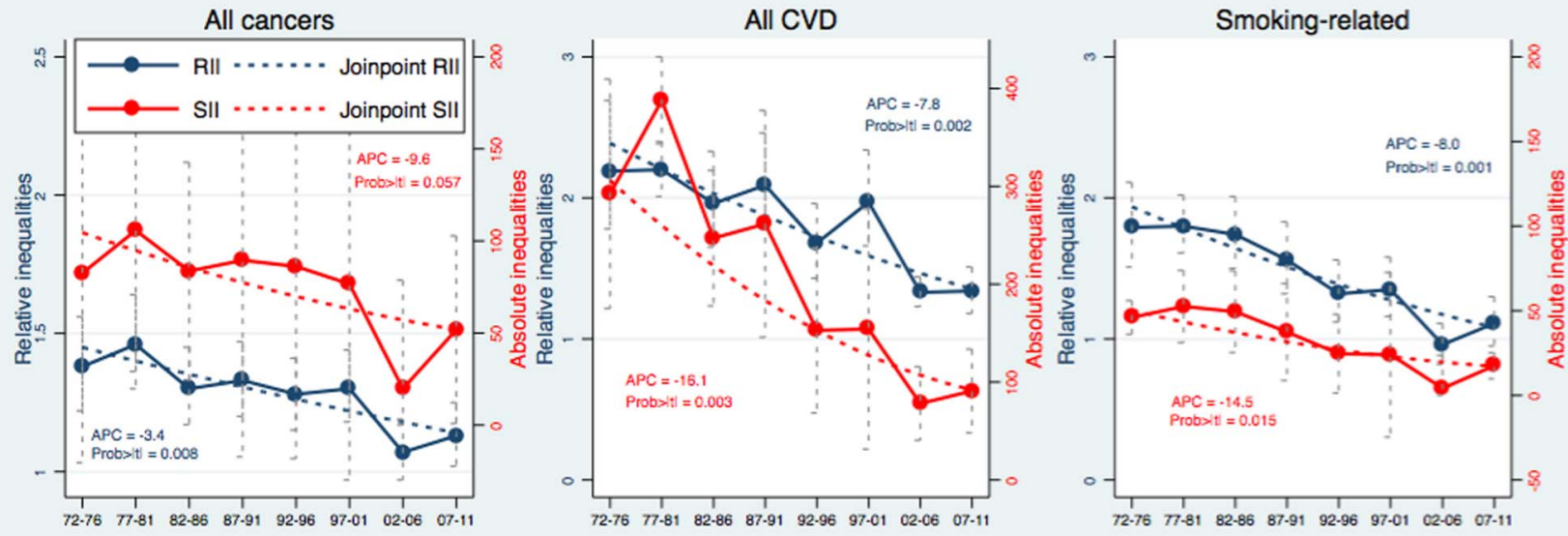

Alcohol-related

Lung cancer

\section{Breast cancer}
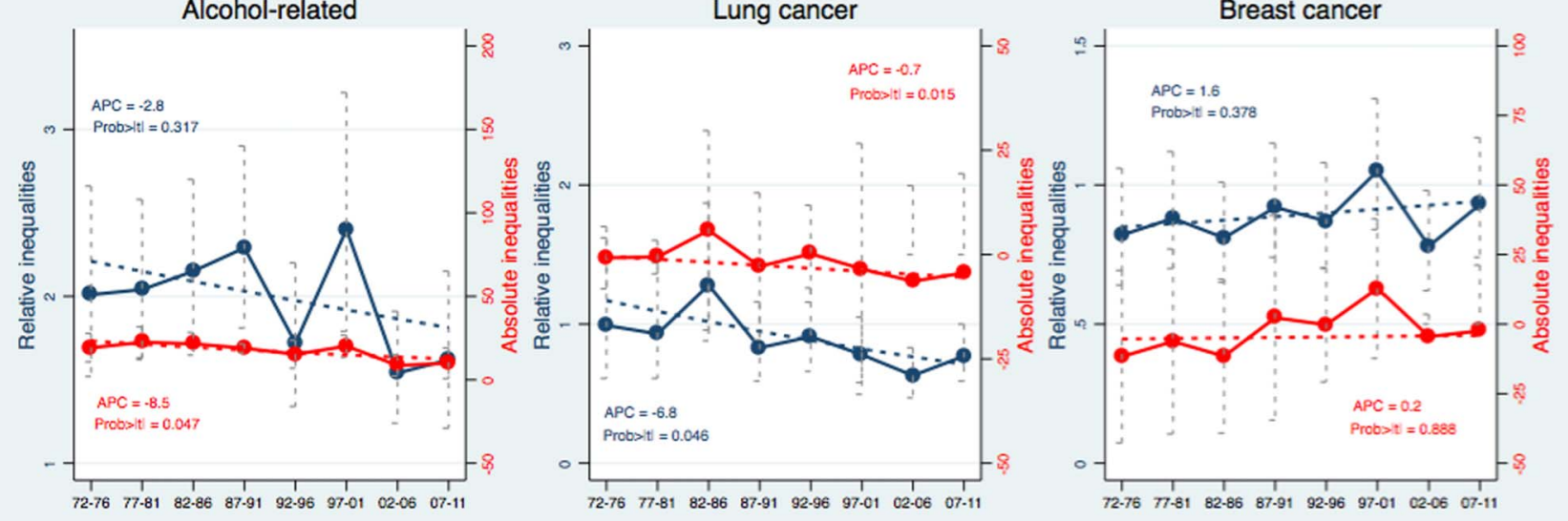

Figure 3 Trends in relative and absolute inequalities for cause-specific mortality among women of the Turin Longitudinal Study (1972-2011), age 30-99 years. The figure showing SII, RII (and their 95\% CI) and the linear prediction for trend across the four decades (SII, Slope Index of Inequality; RII, Relative Index of Inequality; $\mathrm{p}$ trend, $\mathrm{p}$ for test for linear trend).

net of some small advantages of the most privileged at the time of introduction of innovations or because of their ability to better exploit new information and seek for solutions. ${ }^{44}$ This hypothesis is confirmed by the steep decline in mortality for all educational groups, which seems to be even steeper for people with a low educational level, above all, in cardiocirculatory diseases where the expected impact of medical innovations on mortality is stronger and concerns both genders.

The fact that relative educational inequalities remained stable in men and decreased in women may be explained by changes in the distribution of the population by educational level over the study period. Secular trends in educational attainment are observed worldwide, ${ }^{45}$ with younger cohorts generally attaining at higher levels of education as a result of higher public investments in education and of changes in the labour market. This phenomenon clearly appears in our data, with a shrinking of the proportion of the population with primary education, and an increase in the proportion of graduates; these changes were particularly pronounced among women. Because education is likely to impact mortality directly, increasing educational levels in a population potentially contribute to declines in age-standardised mortality rates. ${ }^{45}$ However, the impact of this process on educational inequalities in mortality is less clear. Compulsory schooling reforms have gradually increased the number of years of mandatory education, leaving only marginalised or sick individuals in the lowest educational category, while the number of people achieving a university education has increased. Under these circumstances, if intergenerational upward mobility is experienced by healthier and more capable individuals, ${ }^{46}$ while stable low individuals (with respect to their class of origin) are the sickest, ${ }^{47}$ inequalities in health by educational level may increase. On the other hand, the fact that individuals from lower social classes achieve higher educational levels than their parents because of schooling reforms, may lower the overall health status of higher educational categories, as upwardly mobile individuals were potentially exposed to less advantaged early life conditions than their stable high counterparts. ${ }^{48}$ This phenomenon may contribute to decrease of inequalities in health. ${ }^{49}$ Overall, the marked decline in absolute inequalities and the general stability of relative inequalities in mortality are probably a consequence of decreasing socioeconomic inequalities in the Turin population over the years. However, some of the decrease in inequalities in mortality in women may also be due to the increase in mortality rates of women with university education in the last decade.

The observed patterns of inequalities in mortality may also be explained by secular changes in the social patterning of major risk factors for chronic diseases. The effect of the social transition of lifestyle-related risk factors is particularly evident for the smoking epidemic, with individuals of high education being early adopters and early quitters of the smoking habit, process that generally happens earlier in men than women. ${ }^{50}$ Given the time lag between exposure to smoking and smoking-related mortality, inequalities related to smoking are expected to show 
an inverse gradient at the beginning of the epidemic (higher mortality in individuals with high education), to disappear next, and to rise again when the effect of the switching gradient in smoking prevalence starts having an impact on smoking-related mortality. In our study, inequalities in smoking-related and lung cancer mortality increased among men, reflecting higher smoking rates in men with low versus high education across the study period. ${ }^{43}$ Among women, both absolute and relative inequalities in smoking-related deaths decreased over the study period while relative inequalities in lung cancer mortality were inexistent in 1971-1976, and tended to appear in favour of the less educated women over the end of the study period, probably as a consequence of increasing ASMR among the higher educational groups (see online supplementary figure S5). Results for lung cancer are in line with Italian findings of higher smoking rates among women with a high education at the beginning of the study period and among older women at the end of the study period, ${ }^{43}$ and are similar to those reported in a recent Spanish study. ${ }^{12}$ Decreasing absolute and relative inequalities in smoking-related mortality, on the other hand, may be explained by the fact that this category comprises heterogeneous causes of death which may be influenced by factors other than smoking. Although our results depict favourable trends in smoking-related and lung cancer mortality for the lower educational groups among women, it should be considered that the prevalence of smoking is higher among the higher educational groups among older women (ie, $>50$ years old), but the inverse pattern is observed among younger women. ${ }^{43}$ It is therefore possible that the effect of the reversal in the socioeconomic gradient in smoking in women is still not visible in mortality rates but that educational inequalities in smoking-related causes may increase in the future.

The substantial declines in educational inequalities in alcoholrelated mortality, on the other hand, probably reflect the general pattern of decreasing alcohol consumption observed in southern European countries. ${ }^{51}$ Indeed, alcohol consumption has greatly declined in Italy over the years and heavy consumption is today more prevalent among men and women with a higher educational level. ${ }^{52}$ Inequalities for CVD also substantially decreased in men and women. In the context of falling CVD mortality rates, narrowing of absolute inequalities with converging mortality rates is to be expected and frequently observed. ${ }^{53}{ }^{54}$ In our study, narrowing relative inequalities among women may be explained by the increased ASMR in the highest educational group in the past 10 years and by a decrease in the lowest educated women. The prevalence of obesity and diabetes, on the other hand, has considerably increased especially among individuals with a low socioeconomic status, ${ }^{52} 55$ but these trends do not seem to have impacted inequalities in CVD mortality yet. Rather, a substantial decrease in inequalities in CVD mortality may be due to an equal access to healthcare benefits, such as hypertension, high cholesterol and chronic angina detection and treatment, across educational groups, as suggested in a recent study. ${ }^{56}$

Absolute inequalities in breast cancer mortality, favouring the lower educational groups at the beginning of the study period, tended to disappear over the study period as expected, given the higher potential for reduction in mortality among women with secondary education (experiencing the higher mortality rates). However, ASMRs suggest that the association between education and mortality is not linear and suffers from substantial fluctuations across the study period. Therefore, the summary linear measures RII and SII may not be appropriate to judge trends in this case. Trends in educational inequalities in mortality are influenced by patterns of reproductive behaviours (affecting incidence) as well as by therapeutic improvements and early breast cancer diagnosis (affecting survival) occurred in the last decades. In Italy over the study period, inequalities in breast cancer incidence remained stable over time, ${ }^{57}$ suggesting a major impact of improvements in survival.

\section{Strengths and limitations of the study}

The major strength of this study is the use of a very large data set including all inhabitants of the city of Turin followed up for mortality through national mortality statistics for four decades. To our knowledge, this is one of the first studies of this type in an Italian population. This study also has some limitations. First, individuals who left Turin could not be followed up for mortality, introducing a potential selection bias. However, a previous study concluded that Turin emigrants were generally healthier and more likely to be single than the Turin population, but no significant differences were observed in health conditioned to socioeconomic status. ${ }^{58}$ The dynamic nature of our population may also be responsible for the slight increase of mortality rates in the second 5 -year period following the census. Indeed, if disadvantaged participants are less likely to communicate address changes to the population registry, up to the following census they are considered in the numerator but not in the denominator, creating an artificial increase of RIIs and SIIs towards the end of the 10-year intercensus period. Second, information on health-related behaviours at the individual level was not available, and we were thus unable to directly assess the impact of the changing social distribution of risk factors on inequalities in mortality. Third, this study is limited to the city of Turin, and results cannot be extrapolated to the entire Italian population. However, estimates for inequalities in mortality in Turin are similar to those observed in samples of the Italian population. ${ }^{17}$

\section{CONCLUSIONS}

Absolute inequalities in mortality strongly declined over the study period in both genders. Relative educational inequalities in mortality were generally stable among men, reflecting changes in severity of strong socially patterned diseases; while they tended to narrow among women. In general, this study supports the hypothesis that educational inequalities in mortality have decreased in southern European countries.

\section{What is already known on this subject}

- Inequalities in premature mortality have continued to rise over the last decade in most European countries, but not in southern European countries.

- In Italy, social inequalities in mortality are widely reported but they are generally smaller than in northern European countries.

- Over the past four decades, Italy has experienced great economic, social and cultural transformations that have potentially impacted social inequalities in health and mortality. 


\section{What this study adds}

- This is one of the first studies to assess long-term trends in educational inequalities in all-cause and cause-specific mortality in Europe.

- Absolute inequalities in mortality strongly declined over the study period in both genders.

- Relative educational inequalities in mortality were generally stable among men while they tended to narrow among women.

Contributors SS analysed the data and drafted the first and successive versions of the manuscript. TS, NZ and GC wrote parts of the manuscript and contributed to the interpretation of results. MS, NZ, MD and RO analysed the data and contributed to the interpretation of results.

Funding This research was made possible by a grant from the CCM 2011 titled 'Analisi delle raccolte dati esistenti ed ingegnerizzazione/reingegnerizzazione dei flussi dei dati di interesse sanitario nazionale'. SS is supported by an Ambizione Grant (n PZ00P3_147998) from the Swiss National Science Foundation (SNSF).

Competing interests None declared.

Provenance and peer review Not commissioned; externally peer reviewed.

\section{REFERENCES}

1 Araujo F, Gouvinhas C, Fontes F, et al. Trends in cardiovascular diseases and cancer mortality in 45 countries from five continents (1980-2010). Eur J Prev Cardiol 2013;21:1004-17.

2 Jemal $A$, Ward $E$, Hao $Y$, et al. Trends in the leading causes of death in the United States, 1970-2002. JAMA 2005;294:1255-9.

3 Strand BH, Groholt EK, Steingrimsdottir OA, et al. Educational inequalities in mortality over four decades in Norway: prospective study of middle aged men and women followed for cause specific mortality, 1960-2000. BMJ 2010;340: c654.

4 Unal B, Critchley JA, Capewell S. Explaining the decline in coronary heart disease mortality in England and Wales between 1981 and 2000. Circulation 2004;109:1101-7.

5 Hardoon SL, Whincup PH, Lennon LT, et al. How much of the recent decline in the incidence of myocardial infarction in British men can be explained by changes in cardiovascular risk factors? Evidence from a prospective population-based study. Circulation 2008;117:598-604

6 Jemal $A$, Ward $E$, Anderson RN, et al. Widening of socioeconomic inequalities in U.S. death rates, 1993-2001. PLOS ONE 2008;3:e2181.

7 Mackenbach JP, Bos V, Andersen O, et al. Widening socioeconomic inequalities in mortality in six Western European countries. Int J Epidemiol 2003:32:830-7.

8 Scholes S, Bajekal M, Love $H$, et al. Persistent socioeconomic inequalities in cardiovascular risk factors in England over 1994-2008: a time-trend analysis of repeated cross-sectional data. BMC Public Health 2012;12:129.

9 Phillimore $P$, Beattie $A$, Townsend $P$. Widening inequality of health in northern England, 1981-91. BMJ 1994;308:1125-8.

10 Mackenbach JP, Kulhanova I, Menvielle G, et al. Trends in inequalities in premature mortality: a study of 3.2 million deaths in 13 European countries. J Epidemiol Community Health 2014;69:207-17; discussion 205-6.

11 Kondo N, Rostila M, Yngwe MA. Rising inequality in mortality among working-age men and women in Sweden: a national registry-based repeated cohort study, 1990-2007. J Epidemiol Community Health 2014;68:1145-50.

12 Reques L, Giraldez-Garcia C, Miqueleiz E, et al. Educational differences in mortality and the relative importance of different causes of death: a 7-year follow-up study of Spanish adults. J Epidemiol Community Health 2014;68:1151-60.

13 Strand BH, Steingrimsdottir OA, Groholt EK, et al. Trends in educational inequalities in cause specific mortality in Norway from 1960 to 2010: a turning point for educational inequalities in cause specific mortality of Norwegian men after the millennium? BMC Public Health 2014;14:1208.

14 Martikainen P, Ho JY, Preston S, et al. The changing contribution of smoking to educational differences in life expectancy: indirect estimates for Finnish men and women from 1971 to 2010. J Epidemiol Community Health 2013:67:219-24.

15 Federico B, Mackenbach JP, Eikemo TA, et al. Educational inequalities in mortality in northern, mid and southern Italy and the contribution of smoking. J Epidemiol Community Health 2013;67:603-9.
16 Mackenbach JP, Stirbu I, Roskam AJ, et al. Socioeconomic inequalities in health in 22 European countries. N Engl J Med 2008;358:2468-81.

17 Marinacci C, Grippo F, Pappagallo M, et al. Social inequalities in total and cause-specific mortality of a sample of the Italian population, from 1999 to 2007. Eur J Public Health 2013;23:582-7.

18 Federico B, Costa G, Kunst A. Educational inequalities in initiation, cessation, and prevalence of smoking among 3 Italian birth cohorts. Am J Public Health 2007:97:838-45

19 de Vogli R, Gnesotto R, Goldstein M, et al. The lack of social gradient of health behaviors and psychosocial factors in Northern Italy. Soz Praventivmed 2005:50:197-205.

20 James WP, Nelson M, Ralph $A$, et al. Socioeconomic determinants of health. The contribution of nutrition to inequalities in health. BMJ 1997;314: 1545-9.

21 Stringhini S, Sabia S, Shipley M, et al. Association of socioeconomic position with health behaviors and mortality. JAMA 2010;303:1159-66.

22 Lynch JW, Smith GD, Kaplan GA, et al. Income inequality and mortality: importance to health of individual income, psychosocial environment, or material conditions. BMJ 2000;320:1200-4.

23 Lynch JW, Kaplan GA, Shema SJ. Cumulative impact of sustained economic hardship on physical, cognitive, psychological, and social functioning. N Engl J Med 1997:337:1889-95.

24 Siegrist J, Marmot M. Health inequalities and the psychosocial environment-two scientific challenges. Soc Sci Med 2004;58:1463-73.

25 Mitchell R, Blane D, Bartley M. Elevated risk of high blood pressure: climate and the inverse housing law. Int J Epidemiol 2002;31:831-8.

26 Lantz PM, House JS, Mero RP, et al. Stress, life events, and socioeconomic disparities in health: results from the Americans' Changing Lives Study. J Health Soc Behav 2005;46:274-88.

27 Lynch JW, Kaplan GA, Salonen JT. Why do poor people behave poorly? Variation in adult health behaviours and psychosocial characteristics by stages of the socioeconomic lifecourse. Soc Sci Med 1997:44:809-19.

28 van Doorslaer E, Masseria C, Koolman $X$, et al. Inequalities in access to medica care by income in developed countries. CMAJ 2006;174:177-83.

29 Kelly-lrving M, Delpierre C, Schieber AC, et al. Do general practitioners overestimate the health of their patients with lower education? Soc Sci Med 2011:73:1416-21

30 Abel T. Cultural capital and social inequality in health. J Epidemiol Community Health 2008:62:e13.

31 Kickbusch IS. Health literacy: addressing the health and education divide. Health Promot Int 2001;16:289-97.

32 Lantz PM, House JS, Lepkowski JM, et al. Socioeconomic factors, health behaviors, and mortality: results from a nationally representative prospective study of US adults. J Am Med Assoc 1998:279:1703-8.

33 Center for Disease Control and Prevention. Alcohol and Public Health: Alcohol-Related Disease Impact. Alcohol-related ICD codes 2015 (cited 15 January 2015). http://apps.nccd.cdc.gov/DACH_ARDI/Default/Report.aspx?

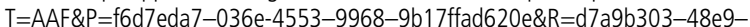
4440-bf47-070a4827e1fd\&F=\&D=\%20last\%20accessed\%2015/1/2015

34 Center for Disease Control and Prevention. Alcohol and Public Health: Alcohol-Related Disease Impact. Alcohol-related ICD codes 2015 [15/1/2015] http://apps.nccd.cdc.gov/DACH_ARDI/Info/ICDCodes.aspx

35 Single $E$, Rehm J, Robson $L$, et al. The relative risks and etiologic fractions of different causes of death and disease attributable to alcohol, tobacco and illicit drug use in Canada. CMAJ 2000;162:1669-75.

36 Waterhouse J, Muir C, Correa P, et al. Cancer incidence in five continents. IARC (International Agency for Research on Cancer). Lyon, 1976.

37 Kunst A, Mackenbach J. Measuring socioeconomic inequalities in health. WHO, Regional office for Europe. Copenhagen, 1994.

$38 \mathrm{Kim} \mathrm{HJ}$, Fay MP, Feuer EJ, et al. Permutation tests for joinpoint regression with applications to cancer rates. Stat Med 2000;19:335-51.

39 ISTAT. Occupati e disoccupati, dati ricostruiti dal 1977-Rapporto. 2013.

40 Bonifazi C, Heins F, Strozza S, et al. The Italian transition from an emigration to immigration country IDEA Working Papers. Vol 5, 2009.

41 Monteleone R, Mozzana C, Rolfini I, eds. The institutional mapping of Italy's education system: Europeanization, centralization and regionalization. 2nd International Workshop, FP7 EU Research Project Making Capabilities WorkWORKABLE; Lausanne, 2011.

42 Mencarini L, Tanturri ML. Familles nombreuses et couples sans enfant: les déterminants individuels des comportements reproductifs en Italie. Population (French Edition) 2006;61:463-91.

43 Federico B, Capelli G, Costa G, et al. Looking at the smoking epidemic through the lens of population pyramids: sociodemographic patterns of smoking in Italy, 1983 to 2005. Popul Health Metr 2012;10:23.

44 Link BG, Phelan JC, Miech R, et al. The resources that matter: fundamental social causes of health disparities and the challenge of intelligence. $J$ Health Soc Behav 2008:49:72-91. 


\section{Other topics}

45 Kulhanova I, Hoffmann R, Judge K, et al. Assessing the potential impact of increased participation in higher education on mortality: Evidence from 21 European populations. Soc Sci Med 2014;117:142-9.

46 Deary IJ, Taylor MD, Hart CL, et al. Intergenerational social mobility and mid-life status attainment: Influences of childhood intelligence, childhood social factors, and education. Intelligence 2005;33:455-72.

47 Manor O, Matthews S, Power C. Health selection: the role of inter- and intragenerational mobility on social inequalities in health. Soc Sci Med 2003; 57:2217-27.

48 Bartley M, Plewis I. Does health-selective mobility account for socioeconomic differences in health? Evidence from England and Wales, 1971 to 1991. J Health Soc Behav 1997;38:376-86.

49 Power C, Matthews S, Manor O. Inequalities in self rated health in the 1958 birth cohort: lifetime social circumstances or social mobility? BMJ 1996:313:449-53.

50 Lopez AD, Collishaw NE, Piha T. A descriptive model of the cigarette epidemic in developed countries. Tob Control 1994;3:242-7.

51 Organisation WH. Status Report on Alcohol and Health in 35 European Countries. 2013.
52 PASSI (Progressi delle Aziende Sanitarie per la Salute in Italia). Diseguaglianze sociali e salute. Rapporto nazionale 2007-2009. 2009.

53 McCartney D, Scarborough $P$, Webster $P$, et al. Trends in social inequalities for premature coronary heart disease mortality in Great Britain, 1994-2008: a time trend ecological study. BMJ Open 2012;2. doi: 10.1136/bmjopen-2011-000737

54 Bajekal M, Scholes S, O'Flaherty M, et al. Unequal trends in coronary heart disease mortality by socioeconomic circumstances, England 1982-2006: an analytical study. PLOS ONE 2013;8:e59608.

55 Palmieri L, Lo Noce C, Vanuzzo D, et al. [Cardiovascular Epidemiologic Observatory: temporal trends of cardiovascular risk factors]. G Ital Cardiol (Rome) 2010:11(5 Suppl 3):31S-6S.

56 Bajekal $\mathrm{M}$, Scholes $\mathrm{S}$, Love $\mathrm{H}$, et al. Analysing recent socioeconomic trends in coronary heart disease mortality in England, 2000-2007: a population modelling study. PLoS Med 2012;9:e1001237.

57 Spadea T, D'Errico A, Demaria $\mathrm{M}$, et al. Educational inequalities in cancer incidence in Turin, Italy. Eur J Cancer Prev 2009;18:169-78.

58 Costa G, Demaria M, Cardano M. Torino: storie di salute in una grande citta. In: Torino CD, ed. Torino, Italia: Comune di Torino, 1998. 